\title{
Proceeding
}

Supplementary Issue: Spring Conferences of Sports Science. Costa Blanca Sports Science Week, 26-28 April 2018. Calpe. Alicante, Spain

\section{Comparative analysis of myocardium repolarization abnormalities in female biathlon athletes with different fitness levels}

\author{
ALEXANDER BOLOTIN¹, VLADISLAV BAKAYEV1 1 , CHUNGUANG YOU² \\ ${ }^{1}$ Institute of Physical Education, Sport and Tourism, Peter the Great St. Petersburg Polytechnic University, \\ Russia \\ 2Linyi University, Shandong, China
}

\begin{abstract}
The problem of studying the heart rate regulation is the most important in the assessment of functional readiness of female athletes to competitive activity. It was found that the main indicator of the fitness degree of the female biathlon athletes is clear consistency between the nervous and hormonal components of the heart rate regulation. Harmonization of both components of the heart rate regulation indicates high adaptive possibilities of the female athletes' organism to the loads. The heart rate regulation was studied with the help of the three-channelled electrocardiograph "Axion". "Varikard 2.51" was used to study the cardiointervalograms. It was established that myocardial repolarization abnormality in female athletes leads to misalignment between the two components of heart rate regulation and, as a consequence, to overtraining. It was revealed that the expressed misalignment between two components of heart rate regulation testifies to poor tolerance of physical loading by sportswomen. It was established that with the help of assessment of myocardium repolarization abnormalities in female athletes it is possible to estimate their functional reserves and effectively manage the training process, as well as to predict excessive physical loads at the early stages. Key words: MYOCARDIUM REPOLARIZATION ABNORMALITIES, ASSESSMENT OF FUNCTIONAL RESERVES, FEMALE BIATHLON ATHLETES, FITNESS LEVEL, COMPONENTS OF HEART RATE REGULATION.
\end{abstract}

Cite this article as:

Bolotin, A., Bakayev, V., \& You, C. (2018). Comparative analysis of myocardium repolarization abnormalities in female biathlon athletes with different fitness levels. Journal of Human Sport and Exercise, 13(2proc), S240-S244. doi:https://doi.org/10.14198/ihse.2018.13.Proc2.08

Corresponding author. Institute of Physical Education, Sport and Tourism, Peter the Great St. Petersburg Polytechnic University, Russia. http://orcid.org/0000-0001-9455-9662

E-mail: vlad.bakaev@gmail.com

Supplementary Issue: Spring Conferences of Sports Science. Costa Blanca Sports Science Week, 26-28 April 2018. Calpe. Alicante, Spain.

JOURNAL OF HUMAN SPORT \& EXERCISE ISSN 1988-5202

(c) Faculty of Education. University of Alicante

doi: 10.14198/jhse.2018.13.Proc2.08

S240 | $2018 \mid$ Proc2 | VOLUME 13

(C) 2018 University of Alicante 


\section{INTRODUCTION}

Currently the conditions of competitive exercises make increased demands on physical training level of the female biathletes. Physical training level of female biathletes is the result of their long-term adaptation to physical activities. It is known that the lower is the tension of the heart regulatory systems at a certain load level, the higher is the level of physical training of ath letes. Decrease of background parasympathetic activity and reactivity of the autonomic nervous system should be regarded as functional violation of normalizing mechanisms of cardiac function regulation. The functional violation of normalizing mechanisms of cardiac function regulation consequentially leads to their failure (Bakaev, et al., 2015; Bunevicius, et al., 2016; Cooper, 1989; Daniel, 2009; Matveyev, 1981; Pityn, et al., 2017; Bolotin, \& Bakayev, 2016).

The correct assessment of myocardial repolarization disorder in biathlon athletes plays a big role in prevention of an overtraining and determination of the status of metabolic processes in the myocardium (Bolotin, \& Bakayev, 2017; Cooper, 1989; Bakaev et al., 2016; Hopkins, et al., 2009).

The evidence from practice shows that training process of the female biathletes is carried out taking into account the status of the mechanisms of nervous (fast) regulation and neurohormonal (slow) regulation of cardiovascular system of their organism. Still there is no consensus among scientists concerning the degree of mismatch between the two components of heart rate regulation, which leads to disorders of myocardial repolarization in female biathletes. Therefore studying of dynamics of interaction factors of nervous and hormonal regulation of heart rhythm in female biathletes with different levels of physical training will help to solve the problem of contraction of myocardial repolarization disorder in female athletes.

Research goal is to compare dynamics of myocardial repolarization factors at female biathletes with the different level of physical training.

Research object. To assess the degree of mismatch between the two components of heart rate regulation in female biathletes with different levels of physical training at rest and under the influence of the same training exercises.

\section{MATERIAL AND METHODS}

Here were studied two 19-aged female biathletes A and B, taking part in the IBU Cup for the Russian national team. Three first training micro-cycles on snow in November and December after the large volume of running work in the snowless summer-autumn period have been taken for comparison. The female athlete A had about $1,700 \mathrm{~km}$ of the done running work to the moment of snow training, and female athlete $B$ had about $1,000 \mathrm{~km}$ of the done running work. During the three first training micro-cycles on snow, both female athletes had the same quantity, volume and intensity of physical load. Every day $300 \mathrm{RR}$ intervals were taken twice a day at rest and once under the influence of training exercises. The obtained data were analysed and exposed to the further all-round statistical processing.

The fractal analysis of the heart rate variability in female biathletes was carried out during the research. The quantitative and qualitative study and comparison of the time series of RR intervals was carried out in female athletes $A$ and $B$ to determine the effectiveness of the fractal components functioning in the blood circulatory system. 
The components characterizing the cardiac function (A1 and $A 2)$ as such, the neurovegetative component (B1 and B2), the status of the pituitary-hypothalamic system (C1 and $\mathrm{C} 2$ ) and the central nervous system (D1 and D2) were assigned to the values of the fractal analysis of the heart rhythm. The values of the fast (nervous) regulation (FRV) included $\mathrm{A} 1, \mathrm{~B} 1, \mathrm{~B} 2, \mathrm{C1}, \mathrm{D} 1$ values, and the values of the slow (hormonal) regulation (SRV) included $A 2, C 2$, D2 values.

During the research were studied: $A 1$ - the combined regulation effect; $A 2$ - a value of own cardiac regulation; $\mathrm{B} 1$ - a value of a vegetative homeostasis of the heart rhythm; $\mathrm{B} 2$ - a value of regulation stability of the heart rhythm; C1 - a value of regulation level of pituitary-hypothalamic system (a nervous regulation component); $\mathrm{C} 2$ - a value of regulation level of pituitary-hypothalamic system (an endocrine regulation component); D1 - a value of the "fast" adaptation to exercise load; D2 - a value of the "slow" adaptation to exercise load.

Based on the obtained data the neurodynamic analysis of the heart rhythm was carried out in female biathletes with the use of the neurodynamic pyramid construction. The values in the left part of the pyramid - anabolism, and in the right part - catabolism were assigned to the indices of the neurodynamic pyramid. The ratio of the left and right parts of the neurodynamic pyramid characterized the dynamics of anabolic and catabolic processes in the body of female athletes under the influence of the training load. The left part was proportional to time of energy resources accumulation, and the right part - to time of energy resources consumption. It was considered that the more is the volume of the energy pyramid, the less is the level of the energy consumption for the performance of the same work at female athletes. It corresponded to the minimum participation of this regulation level in the regulation of the heart rhythm in female athletes. The data on the characteristic of the heart rate rhythm were obtained with the help of the "VNS-Rhythm" device on the basis of calculation and evaluation of statistical parameters of the time series of RR intervals, variation pulsometry, and autocorrelation analysis. They are represented by the complex of values in the form of a statistical characteristic of the time series of cardiac intervals, the RR intervals histogram, autocorrelogram and spectral analysis of heart rate variability. For processing of the cardiointervalogramm and analyzing of the heart rhythm variability was used the "Varicard 2.51 " device.

\section{RESULTS AND DISCUSSION}

The stress status assessment of the regulatory systems of the heart rhythm was evaluated in female athletes at rest and after the exercise load during the research. The state of metabolic processes in the myocardium was determined by ECG changes in the length and height of the $P, R, T$ waves, etc. The changing of the $T$ wave played the basic role in diagnosing the stress state in the regulatory systems of the heart rhythm in female athletes. The research has shown that the tone state of the autonomic nervous system influences the T-wave height. The appearance of the negative T wave, an increase in the QRS complex and a decrease in the S-T segment indicate the development of the myocardial repolarization disorder due to physical overstrain in female biathlete B. It was a consequence of excessive physical activities (Figure 1). 


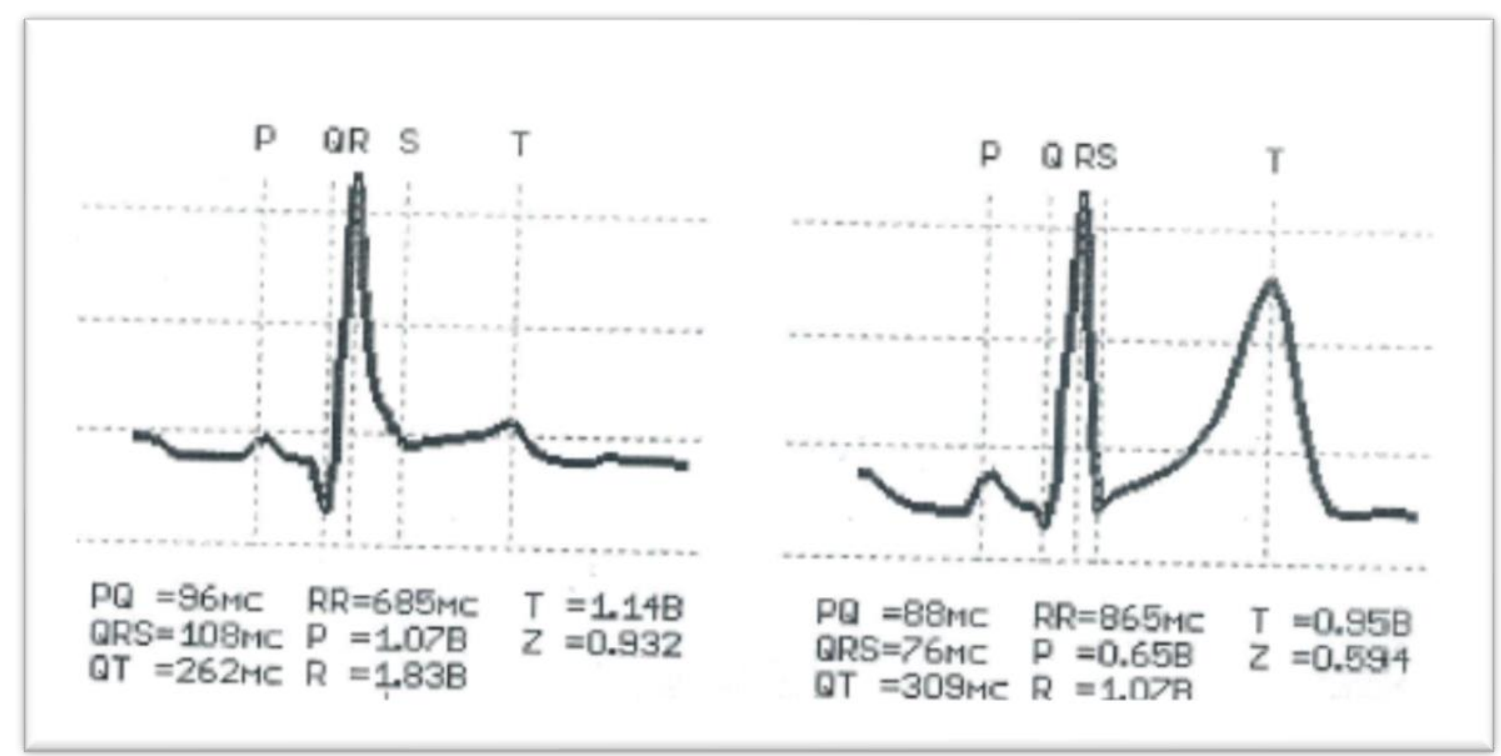

Figure 1. Comparison of T wave changes on the ECG of the female biathlete $A$ (a negative T wave - left figure) and of the female biathlete $B$ (a huge T wave - right figure).

The analysis of the obtained data showed that in the female athlete $A$ at rest during the all research stages the values of the fast FRV regulation (nervous component) considerably exceed the values of the slow SRV regulation (hormone component). The quantitative ratio of these values at rest varies depending on the degree of female athlete exhaustion. It was found that under the influence of daily physical activity the female athlete A had a decrease in the values of the nervous regulation and an increase in the hormonal regulation of the heart rhythm. All this demonstrates the harmonization of two components of neurohormonal regulation of the heart rhythm throughout three training micro-cycles.

The essential increase in the values of nervous regulation and considerable decrease in the values of hormonal regulation was observed in the female athlete B. This indicates that achievement of the high level of physical training couldn't be reached without harmonization maintenance of two parameters of neurohormonal regulation of heart rhythm in female biathlete $B$. Changes in the ECG in the second standard lead (the appearance of a negative T wave, an increase in the QRS complex, and a decrease in the S-T segment) indicate the development of the myocardial repolarization disorder due to physical overstrain of the female athlete.

The appearance of the huge peaked T wave on the ECG in the female athlete B was the result of a mismatch between two levels of neurohormonal regulation.

Thus, the main value of a good recovery after the physical activities during the training is a clear consistency between the nervous and hormonal components of the heart rhythm regulation in female biathletes. The absence of disorders of myocardial repolarization is the result of an accurate consistency between the nervous and hormonal components of the heart rhythm regulation. 


\section{CONCLUSIONS}

During the researches it was established that the female athlete A had significantly higher rates of fast and especially slow heart rate regulation in all cases without exception, in all three microcycles before as well as after training compared to the female athlete $B$.

It was established a different level of state and adaptive opportunities of neurohormonal regulation in female athletes with the different level of physical training.

It was revealed that an expressed mismatch between two components of the heart rhythm regulation indicates a poor tolerance of physical exercises by the female athletes. It was established that by assessment means of myocardial repolarization disorders in female athletes it is possible to assess their functional reserves precisely and to operate the training process effectively and also to predict excessive physical activities at early stages.

\section{REFERENCES}

Bakaev, V.V., Bolotin, A.E., \& Aganov, S.S. (2016). Physical training complex application technology to prepare rescuers for highland operations. Teoriya i Praktika Fizicheskoy Kultury, (6), 6-8.

Bakaev, V.V., Bolotin, A.E., \& Vasil'eva, V.S. (2015). Factors determining sports specialization of cross country skiers. Teoriya i Praktika Fizicheskoy Kultury, (2), 40-41.

Bolotin, A, \& Bakayev V. (2017). Peripheral circulation indicators in veteran trail runners. Journal of Physical Therapy Science, 29(6), 1092-1094. https://doi.org/10.1589/jpts.29.1092

Bolotin, A. \& Bakayev V. (2016). Factors that determine high efficiency in developing speed and strength abilities of female hurdlers. Journal of Physical Education and Sport, 16(3), 910-913.

Bolotin, A. \& Bakayev V. (2017). Method for Training of Long Distance Runners Taking into Account Bioenergetic Types of Energy Provision for Muscular Activity. In Proceedings of the 5th International Congress on Sport Sciences Research and Technology Support, 126-131. https://doi.org/10.5220/0006516101260131

Bunevicius, K, Sujeta A, Poderiene K, et al. (2016). Cardiovascular response to bouts of exercise with blood flow restriction. Journal of Physical Therapy Science, 29(12), 3288-3292. https://doi.org/10.1589/jpts.28.3288

Cooper, K (1989). The aerobics program for total well-being. Physical Education and Sport, Moscow, $224 \mathrm{p}$.

Daniel, S. (2009). Abnormal blood flow in the sublingual microcirculation at high altitude. Eur. J. Appl. Physiol., (106), 473-478.

Hopkins, W., Marshall, S., Batterham, A., \& Hanin, J. (2009). Progressive statistics for studies in sports medicine and exercise science. Medicine \& Science in Sports \& Exercise, 41(1), 3-12. https://doi.org/10.1249/MSS.0b013e31818cb278

Matveyev, L. (1981). Fundamentals of sports training. Moscow: Progress.

Pityn M., Briskin Y., Perederiy A., Galan Y., Tsyhykalo O., Popova I. (2017). Sport specialists' attitude to structure and contents of theoretical preparation in sport. Journal of Physical Education and Sport, 17, Supplement issue 3, 988-994.

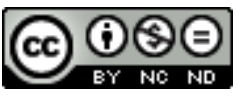

This title is licensed under a Creative Commons Attribution-NonCommercial-NoDerivs 4.0 Unported License. 